\title{
Correction to: Key 5G Physical Layer Technologies
}

\author{
Douglas H. Morais
}

\section{Correction to:}

\section{H. Morais, Key 5G Physical Layer Technologies, https://doi.org/10.1007/978-3-030-51441-9}

The book was inadvertently published without updating the following corrections:

\section{Corrections:}

P. 15: Figure 2.2 was published incorrectly in the original version of the book. The correct version of the figure is updated in the online version of this chapter.

Application Layer
Data Block

TCP Datagram

IP Datagram

\begin{tabular}{|c|c|c|}
\hline $\begin{array}{c}20-60 \text { Byte } \\
\text { IP Header }\end{array}$ & $\begin{array}{c}20 \text { Byte } \\
\text { TCP Header }\end{array}$ & Data Block \\
\hline & 576 Bytes Min., 65,535 Bytes Max. $\longrightarrow$.
\end{tabular}

Fig. 2.2 TCP and IP encapsulation

\footnotetext{
The updated online versions of these chapters can be found at https://doi.org/10.1007/978-3-030-51441-9_2 https://doi.org/10.1007/978-3-030-51441-9_6 https://doi.org/10.1007/978-3-030-51441-9_7 https://doi.org/10.1007/978-3-030-51441-9
} 
P. 16, Line 10 from bottom: The text was processed incorrectly in the original version of the book. The text should read as below:

"The maximum size of a TCP-derived IP datagram is 65,535 bytes".

P. 17, Line 12: The text was processed incorrectly in the original version of the book. The text should read as below:

“eliminated by using IP datagrams no longer than 576 bytes, since all IP...".

P. 104: The presentation of the division processed incorrectly. The corrected presentation of the division is given in the updated online version of this chapter.

P. 147: The caption for Figure 7.13 was processed incorrectly. The correct figure caption is listed below:

Fig. 7.13 Phase noise PSD as per Leeson. Lower, middle, and upper traces are 2, 10, and $30 \mathrm{GHz}$ respectively. (From [8], with permission of Elsevier) 